\title{
Assessment of Durability of Concrete Structure Subject to Carbonation with Application of Safety Factor
}

\author{
Seung-Woo Pack, ${ }^{1}$ Min Sun Jung, ${ }^{2}$ Jun Won Kang, ${ }^{3}$ Ki Yong Ann (iD, ${ }^{2}$ \\ and Janghwan Kim (iD) \\ ${ }^{1}$ Hyundai Engineering and Construction, Yongin 16891, Republic of Korea \\ ${ }^{2}$ Department of Civil and Environmental Engineering, Hanyang University, Ansan 15588, Republic of Korea \\ ${ }^{3}$ Department of Civil Engineering, Hongik University, Seoul 04066, Republic of Korea \\ ${ }^{4}$ Daelim Industrial Corporation Ltd., Seoul 146-12, Republic of Korea
}

Correspondence should be addressed to Janghwan Kim; janghwan.kim1@gmail.com

Received 28 September 2017; Accepted 16 April 2018; Published 27 May 2018

Academic Editor: Aniello Riccio

Copyright (c) 2018 Seung-Woo Pack et al. This is an open access article distributed under the Creative Commons Attribution License, which permits unrestricted use, distribution, and reproduction in any medium, provided the original work is properly cited.

\begin{abstract}
A reliability-based method for identifying appropriate safety factors for use in predicting the service life (i.e., corrosion-free life) of concrete structures subject to carbonation is described in this paper. Reinforced concrete (RC) columns located in $\mathrm{CO}_{2}$-rich urban environments were investigated to estimate their service life. Carbonation depths and cover depths were measured for sound, cracked, and jointed concrete cover conditions. The measurements were used to calculate safety factors for columns subject to carbonation. Goodness-of-fit tests were used to obtain optimal probability distributions for carbonation depths and cover depths. A reliability index of 1.28 , corresponding to a $10 \%$ probability of corrosion initiation, was taken as a threshold for determining the safety factor. The safety factor proposed in this paper can be used to estimate the service life of RC structures subject to carbonation. The sensitivity of the safety factor to the casting method and coefficient of variation of the cover depth were also evaluated.
\end{abstract}

\section{Introduction}

The corrosion of rebar in concrete is an electrochemical process. Carbon dioxide $\left(\mathrm{CO}_{2}\right)$ from the atmosphere diffuses through the pores in concrete and reacts with the pore solution to form carbonic acid. This neutralizes the alkalinity of the concrete and the reaction with calcium hydroxide results in the formation of calcium carbonate, leading to a reduction in the $\mathrm{pH}$ of the pore solution. Normally, the high alkalinity of the concrete pore solution protects the rebar against corrosion by forming a thin oxide layer called a "passivation film" [1]. However, when the effects of carbonation reach through the concrete to the surface of the rebar, the passive film on the steel surface becomes unstable, such that corrosion can be initiated.

The extent of carbonation in concrete depends considerably on a number of factors related to the composition and microstructure of concrete. Internal factors that determine carbonation are properties in concrete as well as hardened concrete properties, such as the type of cement, admixtures, water to binder ratio, and so on. [2]. External factors affecting carbonation include the concentration of $\mathrm{CO}_{2}$, temperature, and relative humidity [3]. The most dangerous range of relative humidity for carbonation is $50 \%$ to $70 \%$ since the carbonation reaction calls for the presence of water, and under higher atmospheric humidity, the diffusion of $\mathrm{CO}_{2}$ is inhibited by water that has filled the pores [4].

It is important to be able to predict the corrosion-free service life of reinforced concrete (RC) structures subject to carbonation [5], given the rebar corrosion mechanism described above. The rate of carbonation is derived from the slope of carbonation depth against the square root of the exposure duration [4]. Several studies have proposed carbonation models, such as a mathematical model based on Fick's law [6], the physicochemical model [3], a twodimensional finite element model [7], and statistical 
models $[8,9]$. Guidelines and standards issued to date have specified two types of analysis procedures for the prediction of RC service life: a full probabilistic method $[10,11]$ and a partial safety factor method $[12,13]$. The full probabilistic method utilizes Monte Carlo simulation approaches [10, 14] to consider the uncertainty of design variables while compensating for variations in both the durability resistance to carbonation and the environmental load of carbonation. However, because of the shortage of relevant statistical data and the complexity of the formulae for load and resistance, the full probabilistic method is limited when determining the service life of RC structures subject to carbonation.

The safety factor method seeks to ensure a prescribed level of reliability for a concrete structure in an urban area over its lifetime using an appropriate design safety factor. This method is simpler than the full probabilistic method, although the latter yields more precise results [15]. The safety factor method for service life prediction is based on reliability theory for structural design. Compared to a structural design approach that specifies safety factors for different load and resistance cases based on reliability theory $[16,17]$, the safety factor method uses an empirical approach with no reliability framework to determine safety factors for the service life analysis of concrete structures subject to carbonation [12, 13]. As an alternative to the safety factor method, a partial safety factor method based on reliability theory can be used, but the formulation of the analysis procedure is deterministic. The formulation of the partial safety factor method is, in general, simpler than that of the full probabilistic method. Therefore, the partial safety factor method can be used practically and efficiently for the design and analysis of an RC structure to ensure sufficient reliability in terms of structural resistance to carbonation over its service life.

In the present study, RC columns subject to carbonation were examined to identify appropriate safety factors for the rational prediction of service life. Data on cover depths and carbonation depths were obtained from the $\mathrm{RC}$ columns of test bridges in service, with the different concrete cover conditions (such as sound, cracked, and jointed) taken into consideration. Based on reliability theory, safety factors for use in the service life analysis of $\mathrm{RC}$ columns subject to carbonation were derived rationally based on the concrete cover conditions, and the service life of the RC columns was estimated using the derived safety factors. In addition, a parametric study was conducted to assess the sensitivity of the safety factors to the concrete casting method and variations in the cover depth due to construction errors.

\section{Field Investigation of Carbonation of RC Columns}

2.1. Environmental Conditions. The reinforced concrete columns of a bridge for a commuter train were examined in terms of carbonation after 18 years of exposure to urban atmospheric conditions in a metropolitan city. Figure 1 shows the railway bridge columns vulnerable to carbonation. The examination was performed in three parts depending on the quality of the hardened concrete. The annual atmospheric

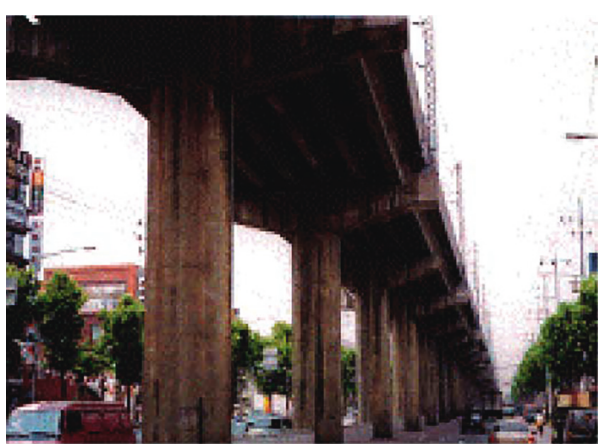

(a)

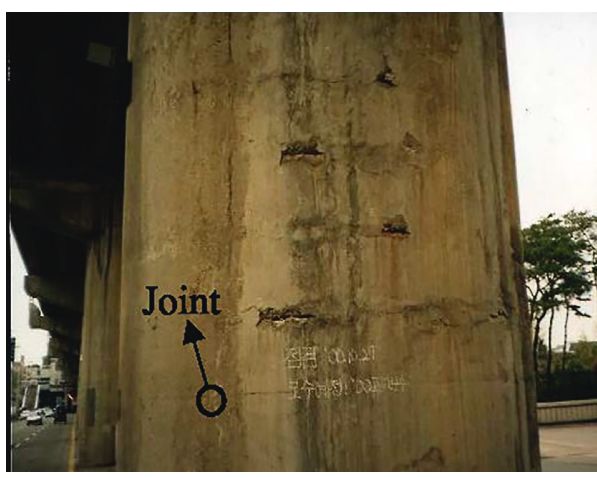

(b)

FIgURE 1: Examples of railway bridge RC columns monitored to assess carbonation effect. (a) Railway bridge. (b) Cracks and joint in the column.

condition is characterized by an average carbon dioxide $\left(\mathrm{CO}_{2}\right)$ concentration of $353 \mathrm{ppm}$, an average relative humidity of $69 \%$, and an average temperature of $12.2^{\circ} \mathrm{C}$. The RC columns of the bridge were somewhat sheltered from the rain by a bridge deck. The concrete mix proportion for the bridge comprised $320 \mathrm{~kg} / \mathrm{m}^{3}$ of ordinary Portland cement, $144 \mathrm{~kg} / \mathrm{m}^{3}$ of water, $813 \mathrm{~kg} / \mathrm{m}^{3}$ of fine aggregate (specific gravity: 2.60 ), and $1062 \mathrm{~kg} / \mathrm{m}^{3}$ of coarse aggregate (specific gravity: 2.65, maximum size: $20 \mathrm{~mm}$ ), and the cover concrete depth to the steel was designed for $50.0 \mathrm{~mm}$. The structure was constructed in 1999, and design compressive strength of concrete used was determined by $30 \mathrm{MPa}$.

2.2. Field Investigation. The carbonation depth, $X_{\mathrm{CO}_{2}}$, and concrete cover depth, $X_{\mathrm{C}}$, were investigated to evaluate the effect of carbonation on the RC columns shown in Figure 1.

2.2.1. Carbonation Depth. $X_{\mathrm{CO}_{2}}$ is defined as the penetration depth of $\mathrm{CO}_{2}$ gas, relative to the concrete surface. The carbonation depth, $X_{\mathrm{CO}_{2}}$, was measured using a phenolphthalein indicator and digital calipers after chipping the surface with a chisel. In the present study, $17 \mathrm{RC}$ railway bridge columns were examined to determine the carbonation depth. A total of 113 samples were collected from these columns. Because of the differences in the quality of the concrete cover at the different sampling locations, the concrete cover conditions were classified as "sound," 
"cracked," or "jointed." Structural samples that were sound did not have any damage, defects, or deterioration. Cracked samples were measured using a visual crack meter, and the width of these cracks usually ranged from 0.1 to $0.2 \mathrm{~mm}$. Jointed parts contained microgaps between two different concrete castings. These gaps can accelerate the transport rate of carbon dioxide and water. Of the $X_{\mathrm{CO}_{2}}$ samples obtained, 56 were sound, 25 were cracked, and 32 were jointed. The samples were obtained by drilling toward an inner part of the cover concrete in increments of $2 \mathrm{~mm}$ and grinding the fragments obtained. The carbonation depth of each sample was determined using a $\mathrm{pH}$ indicator such as phenolphthalein in a solution of water and alcohol [18].

2.2.2. Concrete Cover. The depth of the concrete cover, $X_{\mathrm{C}}$, of the RC columns was estimated using an ultrasonic radar that measures the size and location of the rebar in the concrete using magnetic induction. Using this device, the cover depths of the $17 \mathrm{RC}$ columns were measured at 47 points on each column.

\section{Reliability Analysis}

3.1. Limit State for Carbonation. The durability performance function of a structure can be divided into two parts, the factored resistance $\phi R$ and the factored load $\gamma S$, as shown in the following equation:

$$
g(\phi R, \gamma S)=\phi R-\gamma S .
$$

This equation can be used as the limit state function for the concrete durability with respect to carbonation. In general, the carbonation limit state of an RC structure is defined as the onset of carbonation-induced corrosion of the rebar embedded in the concrete cover (i.e., $X_{\mathrm{CO}_{2}}$ reaching $X_{\mathrm{C}}$ ). For this reason, $X_{\mathrm{CO}_{2}}$ and $X_{\mathrm{C}}$ can be treated as the environmental load $(S)$ and the durability resistance $(R)$, respectively. In order to consider the uncertainty of load and resistance, environmental loads are amplified by appropriate load factors (i.e., environmental load factors), and the resistance is reduced by corresponding resistance factors (i.e., durability resistance factors). Durability is assured if the "factored" resistance is at least equal to the factored load. Thus, the necessary design factors can be developed in order to obtain designs that achieve a prescribed level of reliability. The design factors are of course intended to cover uncertainties and compensate for a lack of complete information.

The limit state function of an RC structure subject to carbonation can be defined as follows:

$$
g=\phi_{\mathrm{c}} X_{\mathrm{c}}-\gamma_{\mathrm{c}} X_{\mathrm{CO}_{2}}
$$

where $\phi_{\mathrm{c}}$ and $\gamma_{\mathrm{c}}$ are the durability resistance factor and environmental load factor for carbonation, respectively.

The safety factor, $\mathrm{SF}_{\mathrm{CO}_{2}}$, for use in the service life estimation of concrete structures subjected to carbonation can be determined as follows:

$$
\mathrm{SF}_{\mathrm{CO}_{2}}=\frac{\gamma_{\mathrm{c}}}{\phi_{\mathrm{c}}}
$$

The carbonation depth of concrete structures has been reported to be proportional to the square root of the exposure time, as expressed in the following equation [19]:

$$
X_{\mathrm{CO}_{2}}(t)=\alpha_{\mathrm{c}} \sqrt{t} \text {, }
$$

where $t$ is the time in years, $X_{\mathrm{CO}_{2}}(t)$ is the carbonation depth in $\mathrm{mm}$, and $\alpha_{\mathrm{c}}$ is the carbonation rate coefficient.

3.2. Probability Density Function. In the partial safety factor method for durability assessment, a safety factor can be determined based on reliability theory. To compute a reliable safety factor, it is necessary to determine optimized probability distributions for $X_{\mathrm{CO}_{2}}$ and $X_{\mathrm{c}}$. In this study, a lognormal distribution was assumed for $X_{\mathrm{c}}$ and a Weibull distribution was assumed for $X_{\mathrm{CO}_{2}}$, based on the results of the goodness-of-fit tests described in a later section.

3.2.1. Weibull Distribution. The Weibull distribution [20] has been suggested by other researchers for use in modeling the reliability and life expectancy of construction materials such as steel and concrete [21]. The probability density function (PDF) and cumulative density function (CDF) of the Weibull distribution are respectively expressed as follows [22]:

$$
\begin{aligned}
& f_{X}(x)=\frac{x_{\mathrm{sh}}}{x_{\mathrm{sc}}}\left[\frac{x}{x_{\mathrm{sc}}}\right]^{x_{\mathrm{sh}}{ }^{-1}} \exp \left[-\left(\frac{x}{x_{\mathrm{sc}}}\right)^{x_{\mathrm{sh}}}\right], \\
& F_{X}(x)=1-\exp \left[-\left(\frac{x}{x_{\mathrm{sc}}}\right)^{x_{\mathrm{sh}}}\right],
\end{aligned}
$$

where $x_{\mathrm{sc}}(>0)$ is a scale parameter and $x_{\mathrm{sh}}(>0)$ is a shape parameter. Here, $x_{\mathrm{sc}}$ is directly related to the failure rate, and as such the failure rate increases with time when $x_{\text {sh }}$ is greater than 1.0. In this study, $x_{\text {sh }}$ values for sound, cracked, and jointed parts are greater than 2.0.

3.2.2. Log-Normal Distribution. The PDF and CDF of the log-normal distribution are as follows:

$$
\begin{aligned}
& f_{X}(x)=\frac{1}{\sqrt{2 \pi}\left(x \cdot x_{\mathrm{sh}}\right)} \exp \left[-\frac{1}{2}\left(\frac{\ln x-x_{\mathrm{sc}}}{x_{\mathrm{sh}}}\right)^{2}\right], \\
& F_{X}(x)=\int_{0}^{x} \frac{1}{\sqrt{2 \pi}\left(x \cdot x_{\mathrm{sh}}\right)} \exp \left[-\frac{1}{2}\left(\frac{\ln x-x_{\mathrm{sc}}}{x_{\mathrm{sh}}}\right)^{2}\right] d x,
\end{aligned}
$$

where $x$ is a random variable, $x_{\mathrm{sc}}$ is a scale parameter, and $x_{\mathrm{sh}}$ is a shape parameter. These parameters are the mean and standard deviation of $\ln x$, respectively.

3.3. Reliability Index. In general, the durability of a structure is evaluated using a failure equation or a limit state function for durability failure. The failure equation is expressed in terms of the environmental load and durability resistance, with input variables grouped together appropriately. From the failure equation, the failure surface can be depicted as shown in Figure 2. For normally distributed load and resistance variables, a reliability index $\beta$ is determined using 


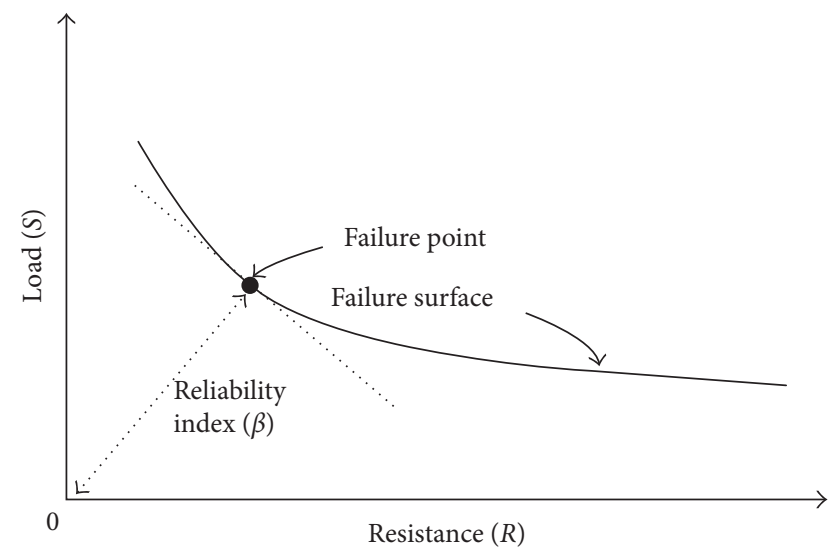

FIgURE 2: Reliability index as a function of load and resistance.

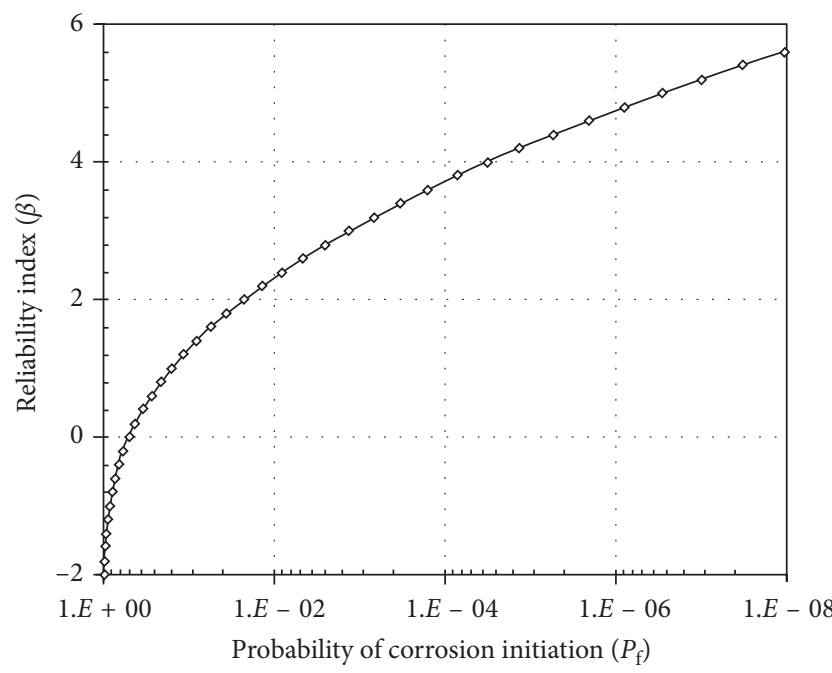

FIgURE 3: Relationship between reliability index and probability of corrosion initiation.

the means and standard deviations of the load and resistance variables, as shown in the following equation:

$$
\beta=\frac{\mu_{R}-\mu_{S}}{\sqrt{\sigma_{R}^{2}+\sigma_{S}^{2}}},
$$

where $\mu_{S}$ and $\mu_{R}$ are the mean values and $\sigma_{S}$ and $\sigma_{R}$ are the standard deviations of load and resistance, respectively.

The reliability index $\beta$ is the shortest distance from the origin to the failure surface. Figure 3 illustrates the relationship between the reliability index and the probability of failure $P_{\mathrm{f}}$ (e.g., the probability of corrosion initiation) [23]. If the random variables are not normally distributed, the probability of failure can be evaluated using equivalent normal distributions [24], as shown in the following equation:

$$
\beta=\frac{\mu_{R}^{N}-\mu_{S}^{N}}{\sqrt{\sigma_{R}^{N^{2}}+\sigma_{S}^{N^{2}}}}
$$

where $\mu_{R}^{N}$ and $\sigma_{R}^{N}$ are the mean value and standard deviation, respectively, of the equivalent normal distribution for the durability resistance variable and $\mu_{S}^{N}$ and $\sigma_{S}^{N}$ are the mean value and standard deviation, respectively, of the equivalent normal distribution for the environmental load variable.

Eurocode [25] established three classes of reliability-RC1, $\mathrm{RC} 2$, and RC3-considering the consequences of structural failures or malfunctions. Further, minimum values for a reliability index were recommended and associated with these reliability classes. The recommended ultimate limit is 3.8, whereas the target reliability index for servicing a structure falls to 1.5. However, Eurocode 1990 does not mention the durability condition of concrete structures. CEB-FIP Model Code [11] proposed minimum values for a reliability index for durability design considering chloride- and carbonationinduced corrosion of steel embedment. This minimum value is set at 1.282 , corresponding to a $10 \%$ probability of failure.

3.4. Equivalent Normal Distribution. The random variables $X_{\mathrm{c}}$ and $X_{\mathrm{CO}_{2}}$, adopted for use in this study, are not normally distributed. Therefore, equivalent normal distributions for the variables are required to determine the failure point coordinates $\delta_{S}$ and $\delta_{R}$ on the failure surface and the reliability index $\beta$ in (8).

The mean values $\left(\mu_{R}^{N}\right.$ and $\left.\mu_{S}^{N}\right)$ and standard deviations $\left(\sigma_{R}^{N}\right.$ and $\left.\sigma_{S}^{N}\right)$ can be derived from the CDF and the PDF corresponding to the equivalent normal distributions [26]. The CDF of the equivalent normal distribution of the environmental load $S$ and resistance $R$ at the failure point coordinates $\delta_{S}$ and $\delta_{R}$ can be written as shown in (9). By rearranging (9), the mean values $\mu_{R}^{N}$ and $\mu_{S}^{N}$ can be computed as shown in (10):

$$
\begin{aligned}
\Phi\left(\frac{\delta_{R}-\mu_{R}^{N}}{\sigma_{R}^{N}}\right) & =F_{R}\left(\delta_{R}\right), \\
\Phi\left(\frac{\delta_{S}-\mu_{S}^{N}}{\sigma_{S}^{N}}\right) & =F_{S}\left(\delta_{S}\right), \\
\mu_{R}^{N} & =\delta_{R}-\sigma_{R}^{N} \Phi^{-1}\left[F_{R}\left(\delta_{R}\right)\right], \\
\mu_{S}^{N} & =\delta_{S}-\sigma_{S}^{N} \Phi^{-1}\left[F_{S}\left(\delta_{S}\right)\right],
\end{aligned}
$$

where $F_{R}\left(\delta_{R}\right)$ is the original CDF of $R$ evaluated at $\delta_{R}$, $F_{S}\left(\delta_{S}\right)$ is the original CDF of $S$ evaluated at $\delta_{S}$, and $\Phi(\cdot)$ is the CDF of the equivalent normal distribution.

The PDF of the equivalent normal distribution of the environmental load $S$ and resistance $R$ at the failure point coordinates $\delta_{S}$ and $\delta_{R}$ can be written as shown in (11) and rearranged to compute $\sigma_{R}^{N}$ and $\sigma_{S}^{N}$ as shown in (12):

$$
\begin{aligned}
\frac{1}{\sigma_{R}^{N}} \phi\left(\frac{\delta_{R}-\mu_{R}^{N}}{\sigma_{R}^{N}}\right) & =f_{R}\left(\delta_{R}\right), \\
\frac{1}{\sigma_{S}^{N}} \phi\left(\frac{\delta_{S}-\mu_{S}^{N}}{\sigma_{S}^{N}}\right) & =f_{S}\left(\delta_{S}\right), \\
\sigma_{R}^{N} & =\frac{\phi\left\{\Phi^{-1}\left[F_{R}\left(\delta_{R}\right)\right]\right\}}{f_{R}\left(\delta_{R}\right)}, \\
\sigma_{S}^{N} & =\frac{\phi\left\{\Phi^{-1}\left[F_{S}\left(\delta_{S}\right)\right]\right\}}{f_{S}\left(\delta_{S}\right)},
\end{aligned}
$$


where $\phi(\cdot)$ is the PDF of the standard normal distribution, $f_{R}\left(\delta_{R}\right)$ is the original PDF of $R$ evaluated at $\delta_{R}$, and $f_{S}\left(\delta_{S}\right)$ is the original PDF of $S$ evaluated at $\delta_{S}$.

3.5. Safety Factor. To determine an appropriate safety factor for use in the durability assessment of RC structures, the most probable failure point $\left(\delta_{S}, \delta_{R}\right)$ corresponding to a carbonation depth $S$ and a cover depth $R$ is first assumed. Then, direction cosines for $R$ and $S$ in (13) can be evaluated using (8), (10), and (12).

$$
\begin{aligned}
& \alpha_{S}=\frac{-\sigma_{S}^{N}}{\sqrt{\sigma_{R}^{N^{2}}+\sigma_{S}^{N^{2}}}}, \\
& \alpha_{R}=\frac{-\sigma_{R}^{N}}{\sqrt{\sigma_{R}^{N^{2}}+\sigma_{S}^{N^{2}}}} .
\end{aligned}
$$

The failure point $\left(\delta_{S}, \delta_{R}\right)$ can be recalculated using the following equation [26]:

$$
\begin{gathered}
\delta_{R}=\mu_{R}^{N}-\alpha_{R} \beta \sigma_{R}^{N}, \\
\delta_{S}=\mu_{S}^{N}-\alpha_{S} \beta \sigma_{S}^{N} .
\end{gathered}
$$

From the failure points (i.e., $\delta_{S}$ and $\delta_{R}$ ) recalculated using (14), the means and standard deviations of the equivalent normal distributions can be reevaluated. When $\delta_{S}$ and $\delta_{R}$ converge, partial safety factors can be calculated using (3) and (15):

$$
\begin{aligned}
& \phi_{\mathrm{c}}=1-\alpha_{R} \beta \omega_{R}, \\
& \gamma_{\mathrm{c}}=1-\alpha_{S} \beta \omega_{S},
\end{aligned}
$$

where $\omega_{R}$ and $\omega_{S}$ are the coefficients of variation (COVs) for $R$ and $S$.

3.6. Calculation of Corrosion Probability. In the present study, the Monte Carlo simulation (MCS) method was used to calculate the probability of corrosion initiation with respect to time for RC columns subject to carbonation. The means and standard deviations of $X_{c}$ and $X_{\mathrm{CO}_{2}}$ were determined from the measurements of the RC columns. Then, 100,000 random samples were simulated for each parameter using the MCS method. The limit state function, $g(t)$, represented by (16), indicates whether an RC column structure is safe with respect to carbonation-induced corrosion:

$$
g(t)=R(t)-S(t)
$$

where $R(t)$ and $S(t)$ are the resistance and environmental load of carbonation-induced corrosion with time, respectively.

If $N$ cycles of trials are conducted to obtain the limit state function, the corrosion probability, $P_{t}$, at time $t$ can be calculated using the following equation:

$$
P_{t}=\frac{n(g(t)<0)}{N},
$$

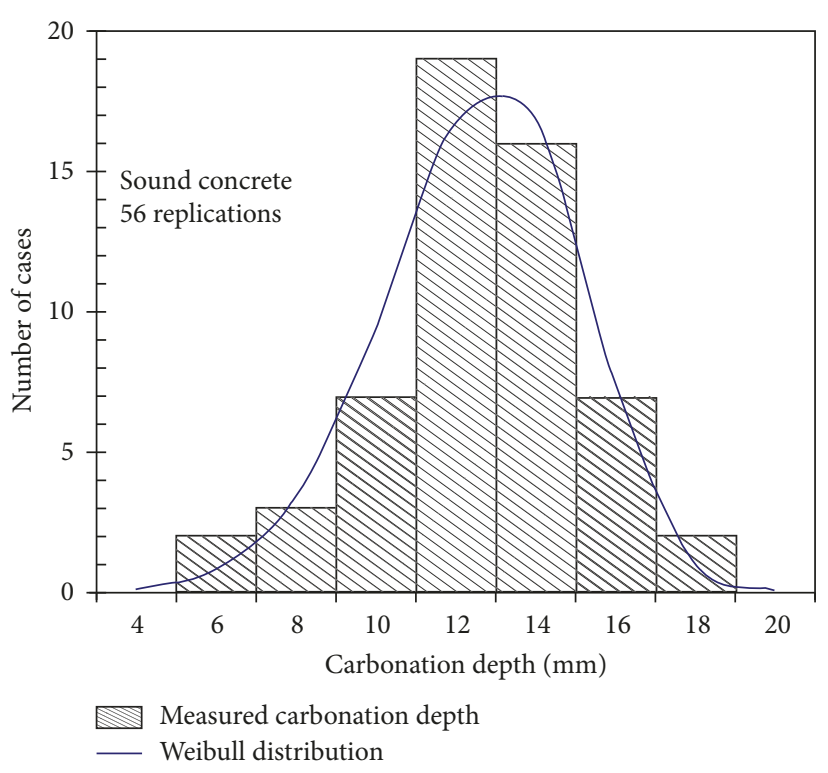

FIGURE 4: Distribution of carbonation depth values obtained from field data for sound concrete.

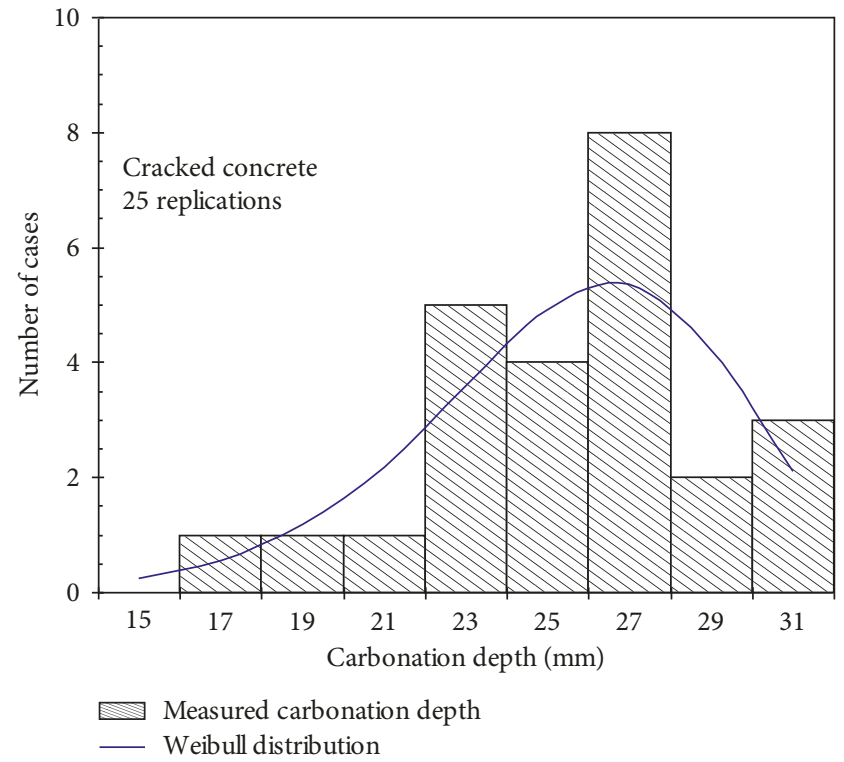

FIgURE 5: Distribution of carbonation depth values obtained from field data for cracked concrete.

where $n\left(g(t)=X_{c}-X_{\mathrm{CO}_{2}}(t)<0\right)$ is the number of occurrences of corrosion initiation in $N$ trials.

\section{Service Life Evaluation Results}

4.1. Parameters Derived from Field Data. Figures 4-6 show histograms of the measured carbonation depths for the RC columns of the test bridges, as well as the relevant Weibull distributions for sound, cracked, and jointed concrete. Figure 7 shows a histogram of the measured concrete cover depths and the relevant log-normal distribution. The means 


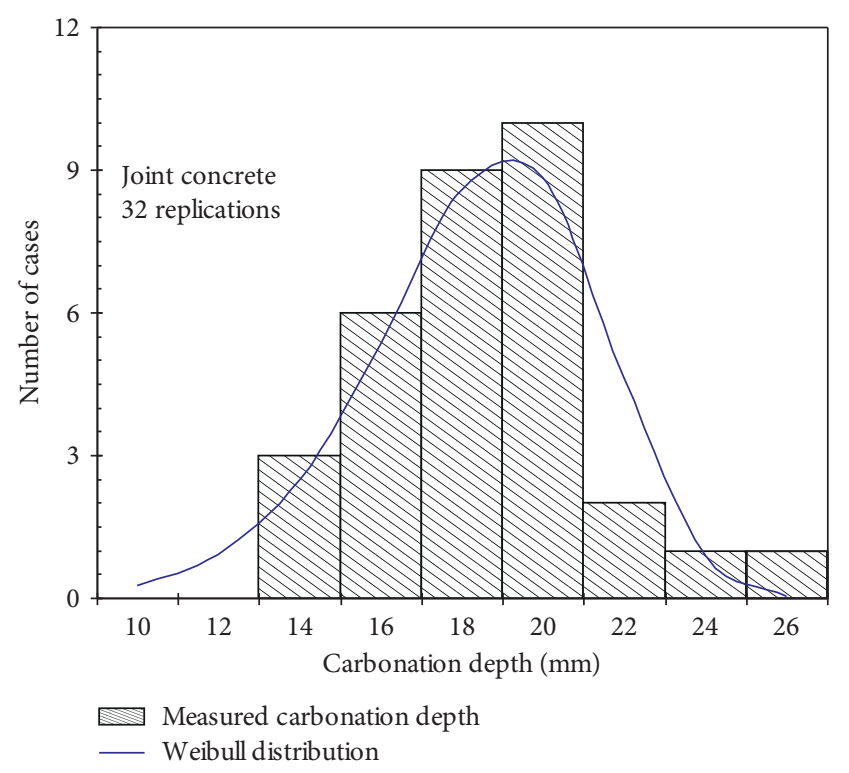

FIGURE 6: Distribution of carbonation depth values obtained from field data for jointed concrete.

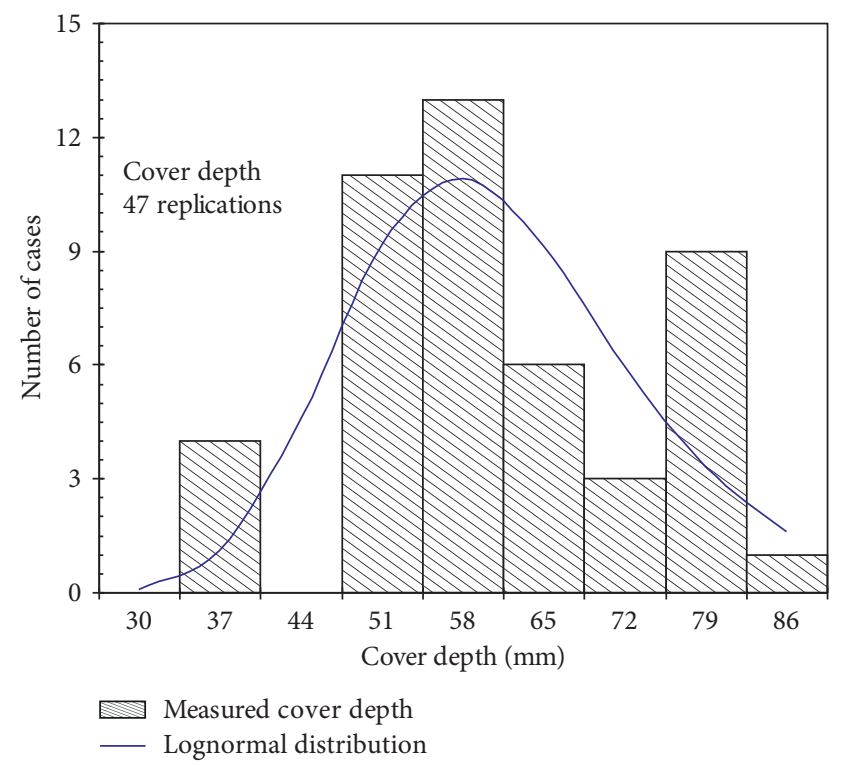

FIgURE 7: Distribution of concrete cover depth values obtained from RC columns.

and standard deviations corresponding to each distribution are summarized in Table 1.

The measurements show that $X_{\mathrm{CO}_{2}}$ for sound concrete ranged from 6 to $18 \mathrm{~mm}$, whereas $X_{\mathrm{CO}_{2}}$ for cracked concrete ranged from 17 to $31 \mathrm{~mm}$, with most of the values being between 23 and $27 \mathrm{~mm}$. The mean value of $X_{\mathrm{CO}_{2}}$ for cracked concrete was approximately twice as large as that for sound concrete. For the jointed concrete, $X_{\mathrm{CO}_{2}}$ ranged from $12 \mathrm{~mm}$ to $26 \mathrm{~mm}$ and the mean value was $17.43 \mathrm{~mm}$. The mean values of $X_{\mathrm{CO}_{2}}$ increased in the order of the sound, jointed, and cracked concrete. The measured values of $X_{\mathrm{c}}$ for the RC columns were widely distributed from
$30 \mathrm{~mm}$ to $86 \mathrm{~mm}$, although the design cover depth of the columns was $67.5 \mathrm{~mm}$.

To derive a partial safety factor for use in the service life assessment of RC structures, it is necessary to identify a probability distribution model that is suitable for the environmental load and durability resistance. A graphical method could be used to identify an optimal probability distribution model. This involves plotting the available data on probability papers prepared for specific distributions. However, the results obtained with the graphical method could be affected by subjective judgment, and thus is unlikely to yield a rational result. Therefore, in this study, widely used goodness-of-fit test methods [27], such as the Chi-square test, Cramér-von Mises test, and Kolmogorov-Smirnov test, were used to determine the optimal probability distributions for the measured values of $X_{\mathrm{CO}_{2}}$ and $X_{\mathrm{c}}$. Based on the goodness-of-fit test results, a Weibull distribution was found to be suitable for modeling the distribution of $X_{\mathrm{CO}_{2}}$, as shown in Figures 4-6, and a log-normal distribution was found to be suitable for modeling the distribution of $X_{\mathrm{c}}$, as shown in Figure 7. The parameters for the Weibull and log-normal distributions were evaluated using a probabilityweighted moment method [28]. The scale and shape parameters of $X_{\mathrm{CO}_{2}}$ and $X_{\mathrm{c}}$ are summarized in Table 1 .

4.2. Safety Factor Evaluation. The safety factor, $\mathrm{SF}_{\mathrm{CO}_{2}}$, for $\mathrm{RC}$ columns subject to carbonation can be calculated according to the procedure described in Section 3.5, using the measured values of $X_{\mathrm{CO}_{2}}$ and $X_{\mathrm{c}}$ for sound, cracked, and jointed concrete. According to the CEB-FIP Model Code [11], as stated above, the minimum value for the reliability index is 1.282 , corresponding to a $10 \%$ probability of the carbonation depth reaching the reinforcing bar in concrete. Durability resistance factors were calculated ranging from 0.758 to 0.776 , whereas the environmental load factor ranged from 1.095 to 1.157 . The safety factors can be obtained by (3) from the calculated load and resistance factors. Thus, safety factors of $1.49,1.44$, and 1.45 were computed for sound, cracked, and jointed concrete, respectively. The COVs of $X_{\mathrm{CO}_{2}}$ for sound, cracked, and jointed concrete were $0.21,0.15$, and 0.17 , respectively. Note that the safety factor tends to be proportional to the COV. Therefore, the COVs of the load and resistance variables could be important factors in assessing the time to corrosion initiation of rebar in RC structures subject to carbonation.

4.3. Service Life Assessment by Safety Factor Method. Figure 8 shows the carbonation depth over time, calculated using (4), for up to 200 years, in increments of five years. Carbonation rate coefficients, $\alpha_{\mathrm{c}}$, were calculated by nonlinear regression of the experimental data for carbonation depth after 18 years of exposure, resulting in values of 2.73, 5.79 , and $4.10 \mathrm{~mm} /$ (year) $^{0.5}$ for sound, cracked, and jointed concrete, respectively. According to Figure 8, the predicted carbonation depths at 100 years are $27.3 \mathrm{~mm}, 57.8 \mathrm{~mm}$, and $41.0 \mathrm{~mm}$ for sound, cracked, and jointed concrete, respectively. The $X_{\mathrm{CO}_{2}}$ value for the cracked concrete is approximately $30 \mathrm{~mm}$ greater than that for the sound concrete. 
TABLE 1: Stochastic parameters for safety factor method.

\begin{tabular}{|c|c|c|c|c|c|c|c|c|}
\hline \multirow{2}{*}{ Variable } & \multirow{2}{*}{ State } & \multirow{2}{*}{ Units } & \multirow{2}{*}{ Replications } & \multicolumn{2}{|r|}{ Values } & \multirow{2}{*}{ Distribution function } & \multirow{2}{*}{$x_{\mathrm{sc}}$} & \multirow{2}{*}{$x_{\mathrm{sh}}$} \\
\hline & & & & Mean & Standard deviation & & & \\
\hline \multirow{3}{*}{ Carbonation depth $(S)$} & Sound & & 56 & 11.62 & 2.45 & \multirow{3}{*}{ Weibull } & 12.52 & 5.64 \\
\hline & Cracked & $\mathrm{mm}$ & 25 & 24.66 & 3.74 & & 26.13 & 7.67 \\
\hline & Jointed & & 32 & 17.43 & 2.88 & & 18.54 & 7.45 \\
\hline Cover depth $(R)$ & - & $\mathrm{mm}$ & 47 & 57.87 & 12.61 & Log-normal & 4.03 & 0.22 \\
\hline
\end{tabular}

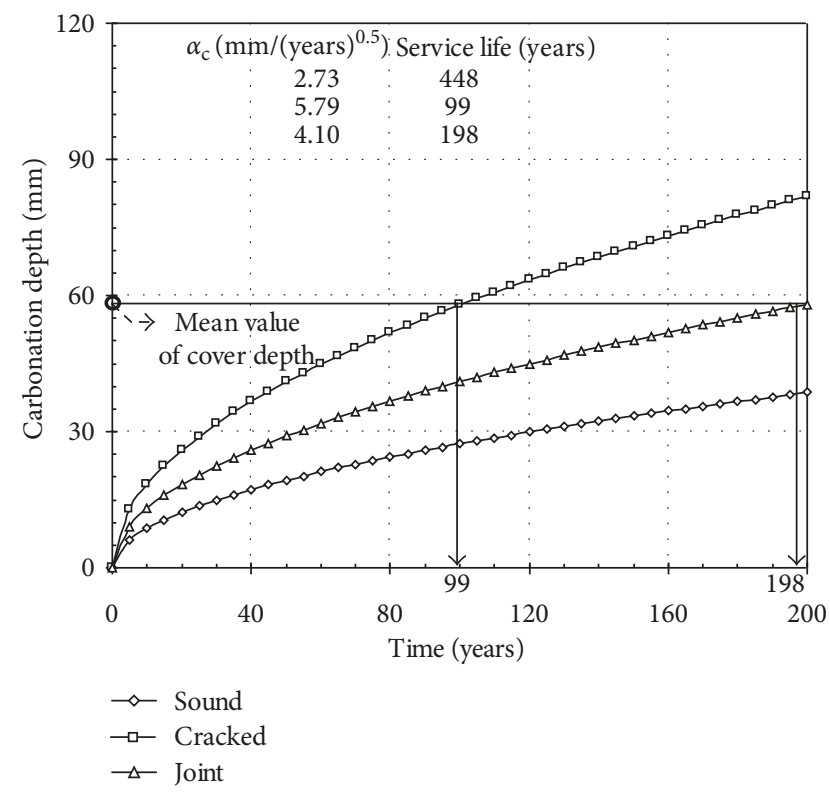

FIGURE 8: Unfactored carbonation depth over time for sound, cracked, and jointed concrete cover.

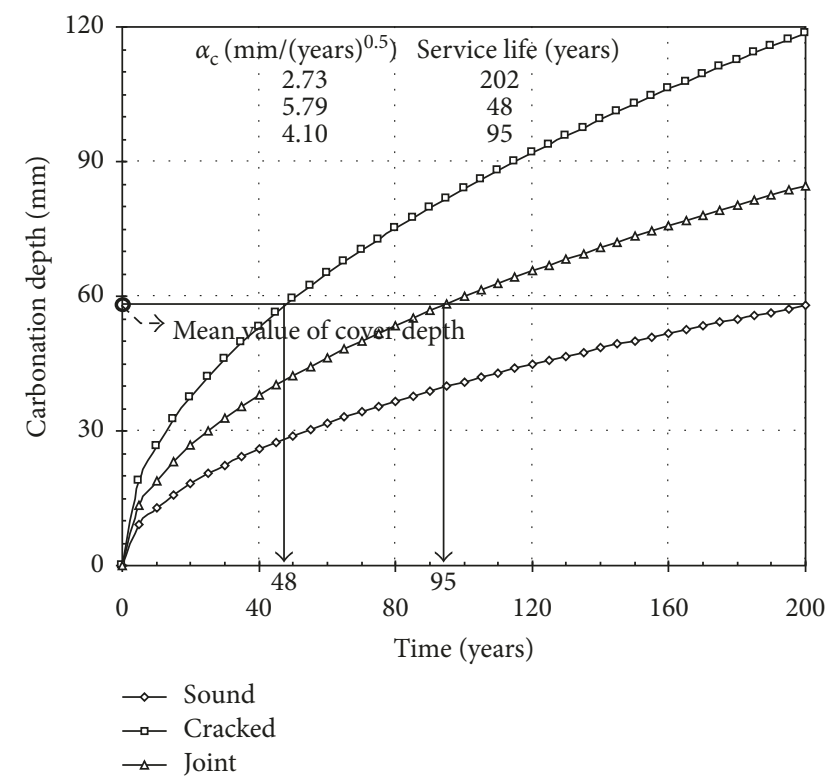

Figure 9: Factored carbonation depth over time for sound, cracked, and jointed concrete cover.

This implies that the presence of cracks in the concrete cover could be an important factor affecting the durability assessment of RC structures subject to carbonation.

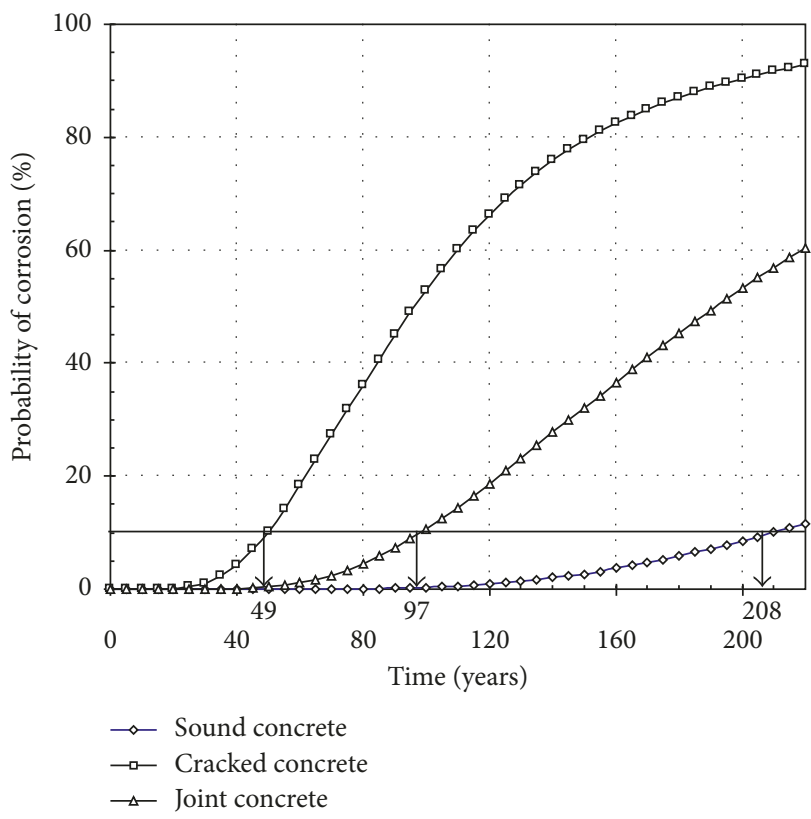

FIGURE 10: Probability of corrosion initiation for RC columns over time.

Figure 9 shows the "factored" carbonation depth for up to 200 years. The factored carbonation depth is determined by multiplying the carbonation depth calculated from (4) by the safety factor given in (3). The carbonation depths at 100 years from (4) are 27.3, 57.9, and $41.0 \mathrm{~mm}$ for sound, cracked, and jointed concrete, respectively. According to Figure 9, the factored carbonation depths at 100 years account for $40.9 \mathrm{~mm}, 83.9 \mathrm{~mm}$, and $59.9 \mathrm{~mm}$, respectively. The $X_{\mathrm{CO}_{2}}$ for the cracked concrete is 1.5 and 2 times greater than those for sound and jointed concrete, respectively. From the graphs of factored carbonation depth, values of 202, 48, and 95 years to corrosion initiation of the steel reinforcement were estimated for the sound, cracked, and jointed concrete, respectively, assuming that corrosion initiates when the corrosion probability exceeds $10 \%(\beta=1.28)$. The "unfactored" carbonation depths at 100 years were estimated to be 448, 99, and 198 years for the sound, cracked, and jointed concrete, respectively, as shown in Figure 8.

4.4. Service Life Assessment by MCS Method. Figure 10 shows the probability of corrosion initiation of rebar in RC columns subject to carbonation using the MCS method described in Section 3.6. The corrosion probability is evaluated separately, based on the quality of the concrete cover (sound, cracked, or jointed). A total of 100,000 simulations 
TABLe 2: Stochastic parameters for Monte Carlo simulation.

\begin{tabular}{|c|c|c|c|c|c|c|c|}
\hline \multirow{2}{*}{ Variable } & \multirow{2}{*}{ State } & \multirow{2}{*}{ Units } & \multicolumn{2}{|r|}{ Values } & \multirow{2}{*}{ Distribution function } & \multirow{2}{*}{$x_{\mathrm{sc}}$} & \multirow{2}{*}{$x_{\mathrm{sh}}$} \\
\hline & & & Mean & Standard deviation & & & \\
\hline \multirow{3}{*}{ Carbonation rate coefficient } & Sound & & 2.73 & 0.56 & \multirow{3}{*}{ Weibull } & 2.95 & 5.64 \\
\hline & Cracked & $\mathrm{mm} /(\text { year })^{0.5}$ & 5.79 & 0.88 & & 6.16 & 7.67 \\
\hline & Jointed & & 4.10 & 0.65 & & 4.37 & 7.45 \\
\hline Cover depth & - & $\mathrm{mm}$ & 57.87 & 12.61 & Log-normal & 4.03 & 0.22 \\
\hline
\end{tabular}

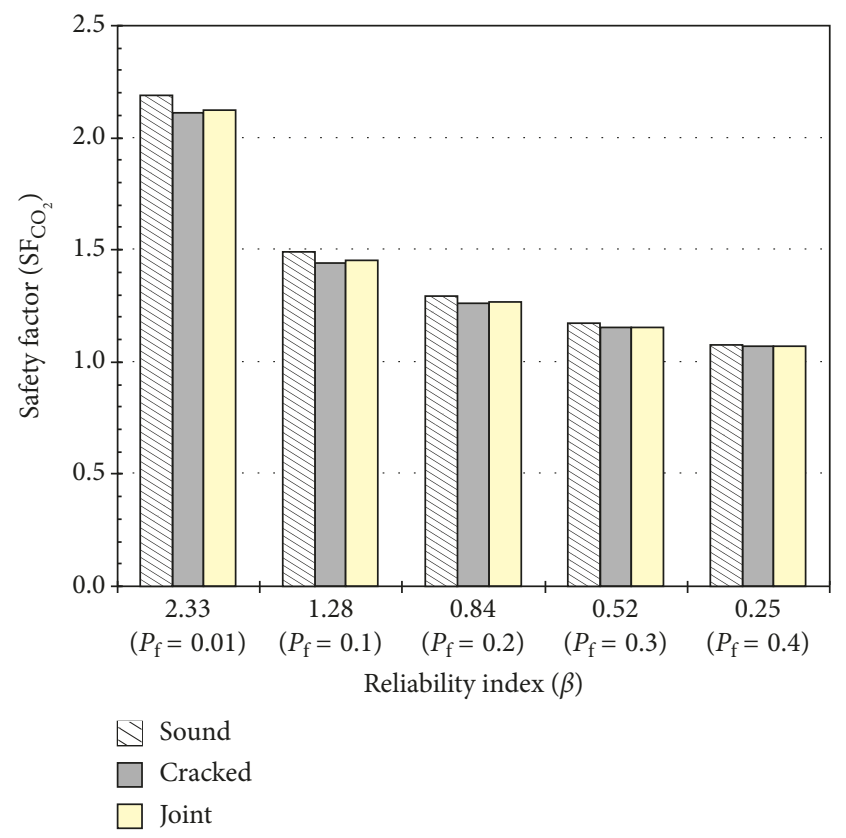

FIGURE 11: Safety factor variation versus reliability index.

were performed to determine the probability of corrosion initiation for each concrete condition, using the optimal distributions for $\alpha_{\mathrm{C}}$ and $X_{\mathrm{C}}$. The stochastic parameter values used in the MCS are listed in Table 2. Taking a probability of $10 \%$ (corresponding to $\beta=1.28$ ) as the threshold for corrosion initiation of RC columns, service life estimates of 208, 49, and 97 years were obtained by the MCS method for sound, cracked, and jointed concrete, respectively. The safety factor method yielded service life estimates of 202, 48, and 95 years for sound, cracked, and jointed concrete, respectively, as shown in Figure 9. These are in good agreement with the estimate obtained by the MCS method. This implies that the service life for an RC structure subject to carbonation can be assessed reasonably well using the safety factor method proposed in this paper.

\section{Discussion}

5.1. Target Reliability. Figure 11 shows the safety factors, $\mathrm{SF}_{\mathrm{CO}_{2}}$, calculated for different reliability indices, $\beta$, for each of the three cover conditions. For a $\beta$ value of 2.33 , which corresponds to a $1 \%$ probability of corrosion initiation, the $\mathrm{SF}_{\mathrm{CO}_{2}}$ values are 2.19, 2.11, and 2.12 for sound, cracked, and jointed concrete, respectively. According to (2), the service life corresponding to these safety factors is 93,22 , and 44 years, respectively, for the three cover conditions. For $\beta=1.28$

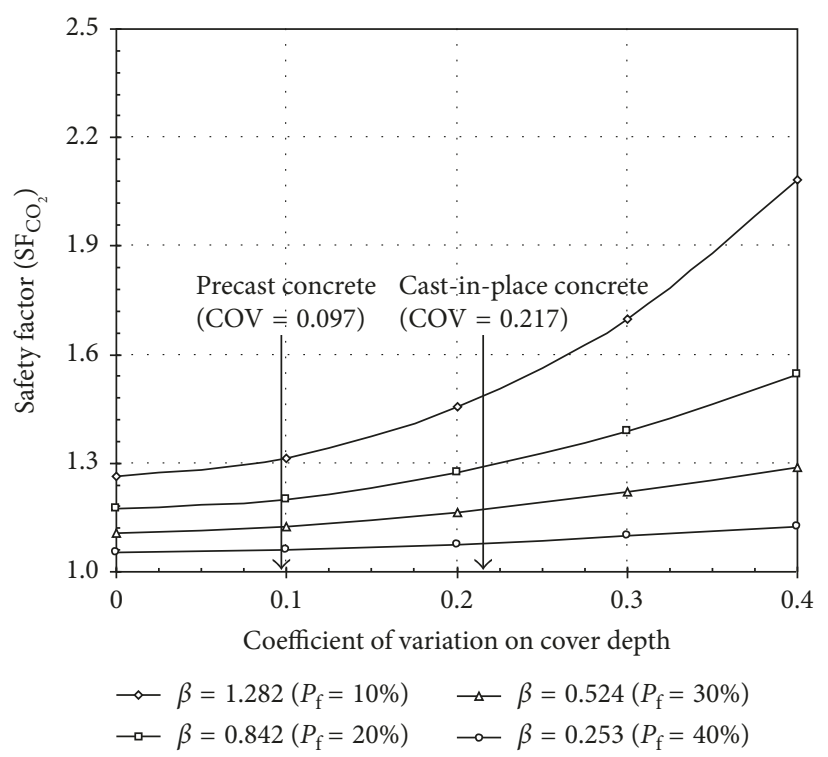

FIGURE 12: Safety factor variation with reliability index.

(equivalent to the reliability index value specified in CEB-FIP for the service life evaluation of a structure [11]), the service life estimates change to 202, 48, and 95 years for sound, cracked, and jointed concrete, respectively.

These results indicate that the target reliability of a concrete structure has a significant effect on the service life of a structure subject to carbonation. The value of $\mathrm{SF}_{\mathrm{CO}}$ decreases by 1.07 to 1.08 when $\beta$ is reduced from 2.33 to 0.25 , as shown in Figure 11. The differences in the $\mathrm{SF}_{\mathrm{CO}_{2}}$ values among the concrete cover conditions for each reliability index range from 0.01 to 0.08 . In other words, the $\mathrm{SF}_{\mathrm{CO}_{2}}$ value is more sensitive to changes in $\beta$ than to differences in the concrete cover. Therefore, it is important to determine reasonable target reliability for use in predicting the corrosion-free life of RC structures subject to carbonation.

5.2. Coefficient of Variation for Cover Depth. Figure 12 shows the relationship between the safety factor and the $\mathrm{COV}$ of the cover depth for different values of the target reliability index in the case of sound cover concrete. For a COV of 0.4, the $\mathrm{SF}_{\mathrm{CO}_{2}}$ values calculated using (3) are 2.08, $1.55,1.29$, and 1.13 for $\beta$ values of $1.28,0.84,0.52$, and 0.25 , respectively. For a COV of zero, the $\mathrm{SF}_{\mathrm{CO}_{2}}$ values are 1.26, $1.17,1.11$, and 1.05 , respectively, for the same target reliability index values. The service life of RC structures predicted using the safety factors calculated for a concrete cover depth COV of 0.4 ranges from 103 to 351 years for the 


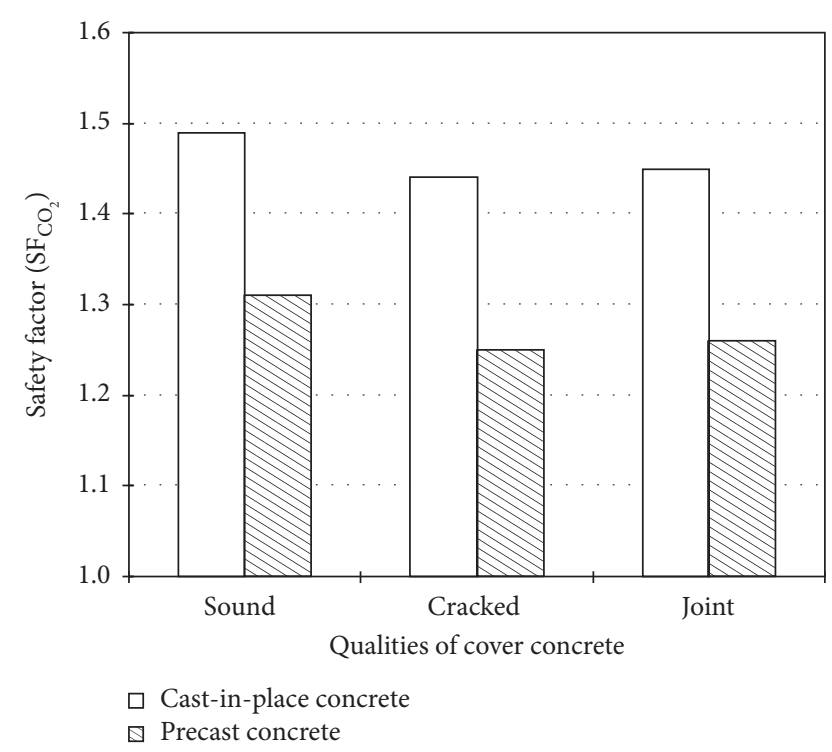

FIGURE 13: Safety factors calculated for precast and cast-in-place concrete members.

TABLE 3: Safety factors for carbonation depending on different states of cover concrete.

\begin{tabular}{lccc}
\hline State & $\begin{array}{c}\text { Durability } \\
\text { resistance factor } \\
\left(\phi_{\mathrm{c}}\right)\end{array}$ & $\begin{array}{c}\text { Environmental } \\
\text { load factor } \\
\left(\gamma_{\mathrm{c}}\right)\end{array}$ & $\begin{array}{c}\text { Safety } \\
\text { factor } \\
\left(\mathrm{SF}_{\mathrm{CO}_{2}}\right)\end{array}$ \\
\hline Sound concrete & 0.776 & 1.157 & 1.49 \\
Cracked concrete & 0.758 & 1.095 & 1.44 \\
Jointed concrete & 0.759 & 1.102 & 1.45 \\
\hline
\end{tabular}

range of $\beta$ values considered. The predicted service life ranges from 283 to 407 years for a COV of zero. These results indicate that variations in the cover depth have a great impact on the time to corrosion initiation of an RC structure. Cover depth is not constant, as is typically assumed by designers; rather, it varies substantially depending on the quality of construction. Therefore, it is important to reduce the variation in cover depth by implementing appropriate quality control practices.

Based on field measurements from cast-in-place columns, the COV of the cover depth is approximately 0.2 . However, it has been reported that the COV of the cover depth for precast concrete cast in a plant is approximately 0.1 [21]. This could be attributed to different manufacturing environments. Precast concrete is made under controlled conditions that make it easier to obtain a more uniform level of quality than is possible with cast-in-place concrete. For this reason, precast concrete has a lower COV than cast-in-place concrete. It is therefore expected that the safety factor for precast concrete will be lower than that for cast-in-place concrete.

As Figure 13 shows, the safety factors for precast concrete columns (i.e., with $\mathrm{COV}=0.1$ ) are $1.31,1.25$, and 1.26 for a sound, cracked, and jointed concrete cover, respectively. The safety factors for cast-in-place concrete columns are $1.49,1.44$, and 1.45 , respectively, for the same three concrete cover conditions, as shown in Table 3. The differences in the safety factors between the cast-in-place and precast concrete columns range from 0.18 to 0.19 . As a result, a shallower cover depth would be required for precast concrete than for cast-inplace concrete to achieve a given service life. For instance, for a 100-year service life and a reliability index of $\beta=1.28$, the required cover depth for the sound concrete condition is $35 \mathrm{~mm}$ for precast concrete and $40 \mathrm{~mm}$ for cast-in-place concrete. This shows that the required cover depth for the design service life of an RC structure may depend on the concrete casting method, even if the structures are placed in the same carbonation environment.

\section{Conclusions}

The conclusions of this study can be summarized as follows:

(1) The probability distributions for the cover depth, $X_{C}$, and carbonation depth, $X_{\mathrm{CO}_{2}}$, of sample RC columns were examined to calculate safety factors for different concrete cover conditions. Average $X_{\mathrm{CO}_{2}}$ values of 11.62, 24.66 , and $17.43 \mathrm{~mm}$ were obtained for the columns for sound, cracked, and jointed concrete cover conditions, respectively. The average value of $X_{c}$ was $57.87 \mathrm{~mm}$.

(2) Goodness-of-fit tests were conducted to identify optimal probability distribution models for $X_{\mathrm{CO}_{2}}$ and $X_{\mathrm{c}}$. Based on the goodness-of-fit test results, Weibull and log-normal distributions were selected to model $X_{\mathrm{CO}_{2}}$ and $X_{\mathrm{c}}$, respectively. The selected distributions match the $X_{\mathrm{CO}_{2}}$ and $X_{\mathrm{c}}$ data well for all the concrete cover conditions.

(3) Safety factors for use in the service life assessment of RC structures subject to carbonation were calculated based on reliability theory. For a reliability index, $\beta$, of 1.28 , corresponding to the value for service life evaluation specified in CEB-FIP [11], safety factors, $\mathrm{SF}_{\mathrm{CO}_{2}}$, of $1.49,1.44$, and 1.45 were calculated for sound, cracked, and jointed concrete, respectively. Based on the calculated $\mathrm{SF}_{\mathrm{CO}_{2}}$ values, service life (i.e., time to rebar corrosion initiation) estimates of 202,48 , and 95 years, respectively, were obtained for the three different concrete cover conditions. The Monte Carlo simulation was used to validate the service life estimates obtained by the safety factor method. The estimated service life values obtained by the two methods were in good agreement. Therefore, the safety factor method proposed in this paper is considered a reasonable approach for estimating the service life of RC structures subject to carbonation. However, the safety factor used in the design specification should be derived from ample data regarding concrete carbonation by laboratory and in situ tests. In this study, only 113 samples were used. Thus, future research should involve collecting and utilizing more experimental data under different environmental conditions and mix proportions in order to determine safety factors.

(4) Safety factor $\left(\mathrm{SF}_{\mathrm{CO}_{2}}\right)$ values of $1.26,1.17,1.11$, and 1.05 were obtained for $\beta$ values of $1.28,0.84,0.52$, and 0.25 , respectively, and a concrete cover COV of 
zero. For an increased concrete cover COV of 0.4 , the corresponding $\mathrm{SF}_{\mathrm{CO}_{2}}$ values increase to $2.08,1.55,1.29$, and 1.13 , respectively. This implies that variation in the cover depth is a critical factor affecting the service life estimation for RC structures. Variation in the cover depth depends largely on the degree of quality control exercised during construction. For instance, a precast concrete member has a much lower COV than a cast-in-place concrete member because of the more controlled manufacturing process. Therefore, if the variation in cover depth is large because of poor construction quality control, an excessively thick cover depth might be estimated to satisfy the design service life using the safety factor method. Therefore, it is important to achieve good construction quality to obtain a reasonable design cover depth.

\section{Conflicts of Interest}

The authors declare that they have no conflicts of interest regarding the publication of this paper.

\section{Acknowledgments}

This research was supported by the Korea Institute of Energy Technology Evaluation and Planning (KETEP) grant (no. 20151520100990) funded by the Ministry of Trade, Industry and Energy of the Republic of Korea.

\section{References}

[1] C. L. Page, "Mechanism of corrosion protection in reinforced concrete marine structure," Nature, vol. 256, no. 5535, pp. 514-515, 1975.

[2] A. M. Neville, Properties of Concrete Properties of Concrete, John Wiley \& Sons, New York, NY, USA, 4th edition, 1995.

[3] V. G. Papadakis, C. G. Vayenas, and M. N. Fardis, "Fundamental modeling and engineering investigation of concrete carbonation," ACI Material Journal, vol. 88, no. 4, pp. 363373, 1991.

[4] Y. H. Loo, M. S. Chin, C. T. Tam, and K. C. G. Ong, "A carbonation prediction model for accelerated carbonation testing of concrete," Magazine of Concrete Research, vol. 46, no. 168, pp. 191-200, 1994.

[5] H.-W. Song, S.-J. Kwon, K. J. Byun, and C.-K. Park, "Predicting carbonation in early-aged concrete," Cement and Concrete Research, vol. 36, no. 5, pp. 979-989, 2006.

[6] M. T. Liang, W. Qu, and C.-H. Liang, "Mathematical modelling and prediction method of concrete carbonation and its applications," Journal of Marine Science and Technology, vol. 10, no. 2, pp. 128-135, 2002.

[7] A. V. Saetta, B. A. Schrefler, and R. V. Vitaliani, "2-D model for carbonation and moisture heat flow in porous material," Cement and Concrete Research, vol. 25, no. 8, pp. 1703-1712, 1995.

[8] T. P. Hills, F. Gordon, N. H. Florin, and P. S. Fennell, "Statistical analysis of the carbonation rate of concrete," Cement and Concrete Research, vol. 72, pp. 87-107, 2015.

[9] A. Silva, R. Neves, and J. de Brito, "Statistical modelling of carbonation in reinforced concrete," Cement and Concrete Research, vol. 50, pp. 73-81, 2014.

[10] DuraCrete, "Probabilistic performance based durability design of concrete structures," Final Tech. Rep., Document
BE95-1347/R17, European Brite-Euram Programme, DuraCrete, Te Awamutu, New Zealand, 2000.

[11] CEB-FIP, Model Code for Service Life Design, Task Group 5.6, The International Federation for Structural Concrete (FIB), Lausanne, Switzerland, 2006.

[12] MOCT, Standard Specification for Concrete Structures on Durability, Ministry of Construction and Transportation, Sejong City, Republic of Korea, 2004, in Korean.

[13] JSCE, Standard Specification for Durability of Concrete, Vol. 108, Concrete Library, Japan Society of Civil Engineers, Tokyo, Japan, 2002, in Japanese.

[14] S.-J. Kwon, H.-W. Song, and M. Q. Feng, "Service life prediction for RC columns based on probabilistic method: Cracks and joints exposed to carbonation," in Proceedings of 5th International Engineering and Construction Conference, Los Angeles, CA, USA, pp. 443-450, 2008.

[15] H.-W. Song, S.-W. Pack, C.-H. Lee, and S.-J. Kwon, "Service life prediction of concrete structures under marine environment considering coupled deterioration," Restoration of Buildings and Monuments, vol. 12, no. 4, pp. 265-284, 2006.

[16] ACI Committee 318, Building Code Requirements for Structural Concrete, ACI 318-05, American Concrete Institute, Detroit, MI, USA, 2005.

[17] MOCT, Standard Specification for Structural Concrete, Ministry of Construction and Transportation, Sejong City, Republic of Korea, 2003, in Korean.

[18] JIS, Method for Measuring Carbonation Depth of Concrete, Japan Industrial Standard. A-1152, JIS, Tokyo Japan, 2002.

[19] J. Kropp, "Relations between transport characteristics and durability," Performance criteria for concrete durability," Rilem Report 12, J. Kropp and H. K. Hilsdorf, Eds., E\&FN SPON, New York, NY, USA, 1995.

[20] W. A. Weibull, "Statistical distribution function of wide application," Journal of Applied Mechanics, vol. 18, no. 3, pp. 293-297, 1951.

[21] H.-W. Song, S.-W. Pack, and K. Y. Ann, "Probabilistic assessment to predict the time to corrosion of steel in reinforced concrete tunnel box exposed to sea water," Construction and Building Materials, vol. 23, no. 10, pp. 3270-3278, 2008.

[22] N. L. Johnson and S. Kotz, Continuous Univariate Distributions-1, Houghton Mifflin Company, Boston, MA, USA, 1970.

[23] C. Edvardsen and L. Mohr, "Designing and rehabilitating concrete structures-Probabilistic approach," in Proceedings of Fifth Canmet/ACI International Conference on Durability of Concrete, pp. 1193-1208, Barcelona, Spain, 2000.

[24] E. Paloheimo and M. Hannus, "Structural design based on weighted fractiles," Journal of Structural Division, vol. 100, pp. 1367-1378, 1974.

[25] British Standard, Eurocode-Basis of Structural Design, BS EN 1990:2002, European Committee for Standardization, London, UK, 2002.

[26] A. H.-S. Ang and W. H. Tang, Probability Concepts in Engineering Planning and Design, Vol. 2, John Wiley \& Sons, Hoboken, NJ, USA, 1990.

[27] J. D. Salas, R. A. Smith, G. Q. Tabios III, and J.-H. Heo, Statistical Computer Techniques in Water Resources and Environmental Engineering, Colorado State University, Fort Collins, CO, USA, 1994.

[28] J. R. M. Hosking, J. R. Wallis, and E. F. Wood, "Estimation of the generalized extreme-value distribution by the method of probability weighted moments," Technometrics, vol. 27, no. 3 , pp. 251-261, 1985. 


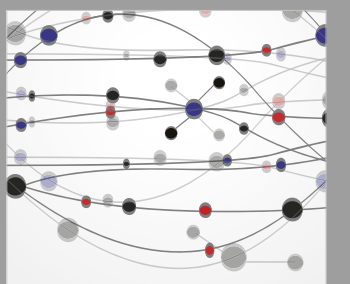

The Scientific World Journal
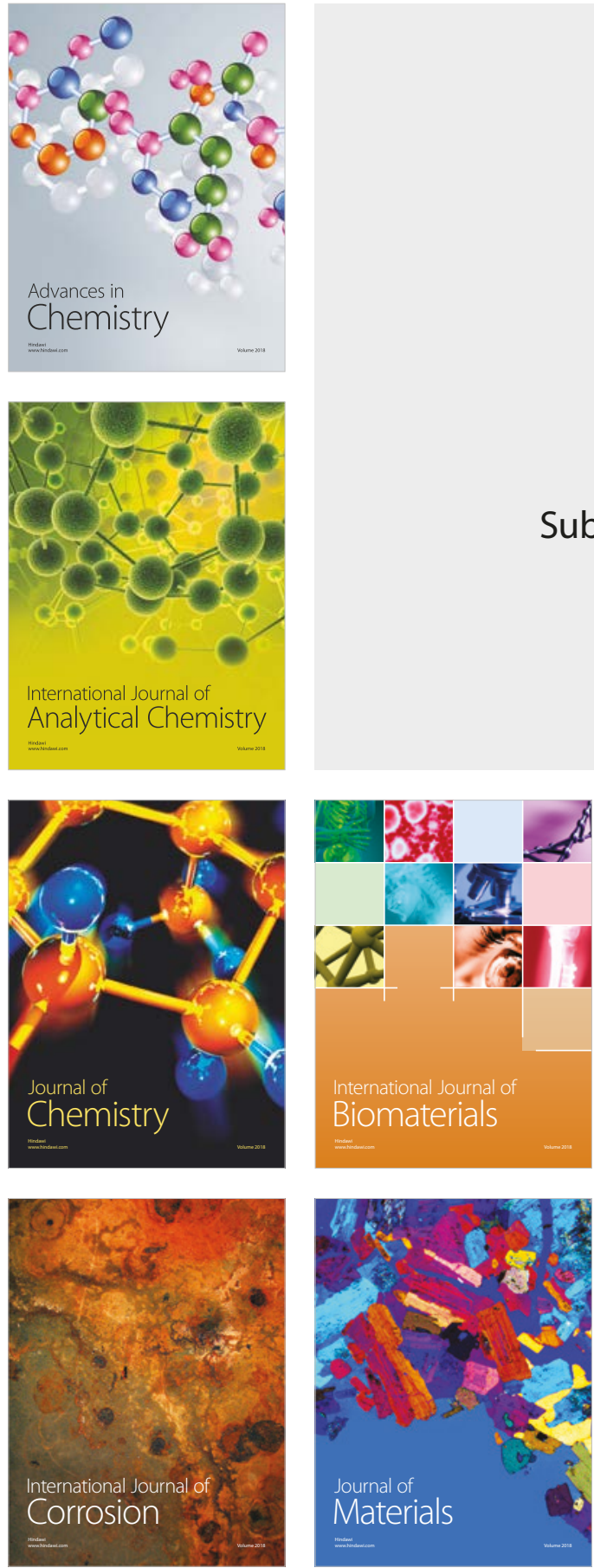

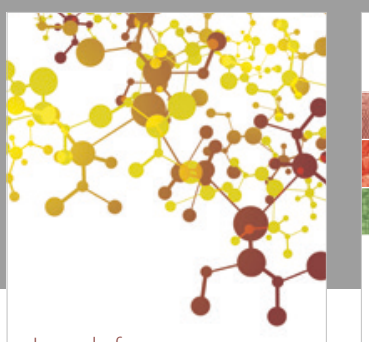

Journal of

Applied Chemistry
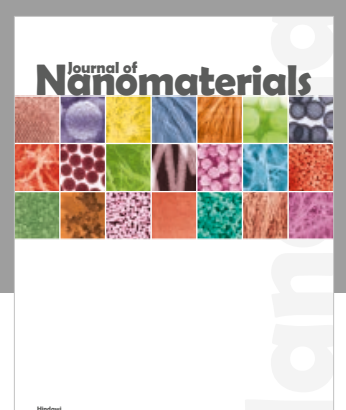

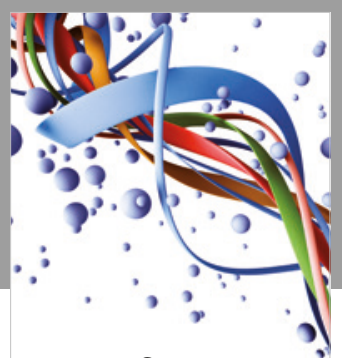

Scientifica

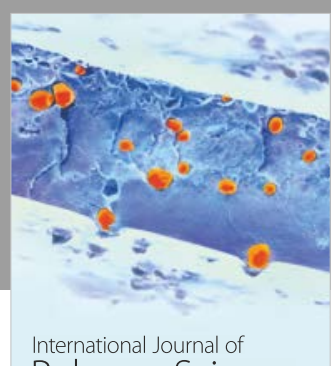

Polymer Science

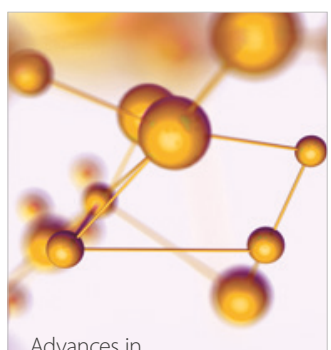

Physical Chemistry
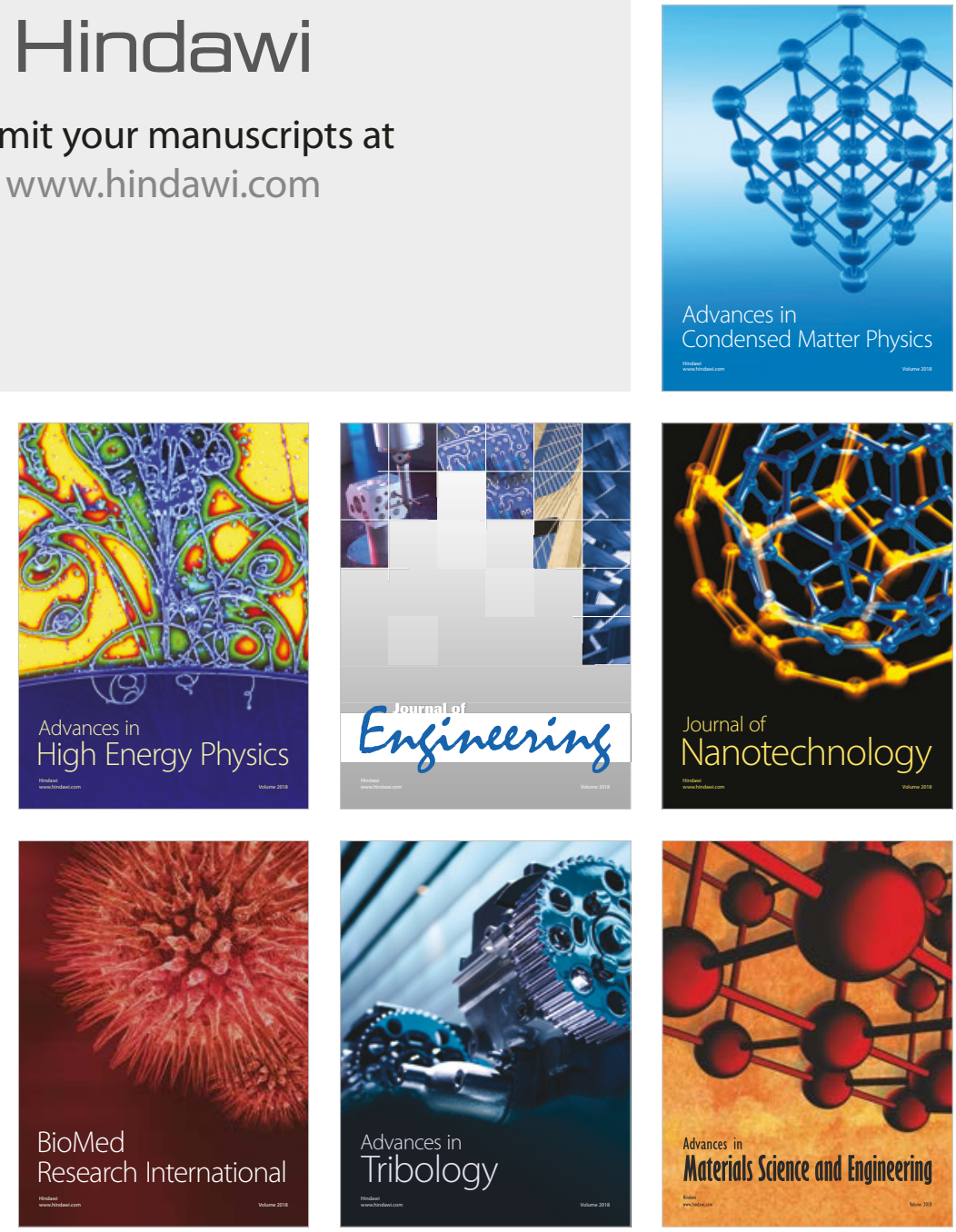